\title{
Editorial
}

\section{Developing Countries: Waste Data Voids and Landfill Site Studies in México}

For developing countries, and particularly México, solid waste management is an issue that surpasses current technical and economical capabilities. The process to acquire and use an integrated waste management has been slow and developing degrees nationwide are enormously different; from the landfill site in Monterrey, N.L. that provides energy for the metropolitan subway, to innumerable waste generation sources representing a black box on how much waste is being generated. Multiple sectors are still in need of waste characterization studies including domestic waste, industrial, higher education centers, public buildings, hospitals and medical practices, penitentiaries, etc.

At the moment, higher education centers are gaining the momentum to develop and enforce proper Waste Management Programs (WMP). Regardless being education centers in the technological aspect, waste management still needs a big effort and education in this topic has to be cultivated, encouraged and rewarded. However, the education and attempts to implement WMP in education centers face a common inertia and sometimes apathy, in all sectors, i.e. Faculty staff, administrators, students and cleaning staff. The problem is then difficult to approach and at the moment it is very common to ignore how much waste is being generated, the characterization of the waste stream and how to handle hazardous waste. Higher education centers in México, particularly in highly populated cities produce a "quiet" although important environmental impact. According to Turcott et al., at the Universidad Tecnológica de León, 83\% of this impact is related to solid waste generation. A first experience in this university comprised waste valorization, design and placement of infrastructure for the primary waste separation, awareness campaigns and diffusion for the community of university on the adequate waste management approach seeking to provide a model for educational institutions. Going a step further in higher education institutions WMP Armijo et al. present in this volume a successful social marketing approach, relying on the participation of students and academic staff rather than depending only on the cleaning personnel.

Municipal solid waste characterization in an urban and rural scenarios offer an insight into the potential valorization of waste. Waste generation in Mexico differs among geographical regions; and the study in the Northern border revealed that up to $43 \%$ of waste would be valuable if recycled. On the other hand, Taboada et al., present an adaptation of the procedure to estimate waste generation rates in a rural context. Although some other reports currently exist on this topic, there is no general consensus on the methodology to obtain the information, making it very difficult to compare results and create trustworthy national indexes. A final contribution to this publication goes to the technical aspect on landfill studies, seeking to provide groundwork on leachate recycling. There is still a lot to be done, and the problem has acquired mammoth proportions. But even a big animal is likely to be defeated by a pack hunting together.

Liliana Márquez-Benavides
(Guest Editor)

(C) Liliana Márquez-Benavides; Licensee Bentham Open.

This is an open access article licensed under the terms of the Creative Commons Attribution Non-Commercial License (http://creativecommons.org/licenses/by$\mathrm{nc} / 3.0 /$ ) which permits unrestricted, non-commercial use, distribution and reproduction in any medium, provided the work is properly cited. 